\title{
BMJ Open Intranasal insulin for treatment of delirium in older hospitalised patients: study protocol for a randomised controlled trial
}

\author{
Anita Nitchingham (D) , ${ }^{1,2}$ Andrew Milne, ${ }^{3}$ Barbara Toson, ${ }^{4}$ Bernard Tuch, ${ }^{5}$ \\ Meera Agar, ${ }^{6}$ Jacqueline Close, $^{1,7}$ Gideon Caplan ${ }^{1,2}$
}

To cite: Nitchingham A, Milne A, Toson B, et al. Intranasal insulin for treatment of delirium in older hospitalised patients: study protocol for a randomised controlled trial. BMJ Open 2021;11:e050765. doi:10.1136/ bmjopen-2021-050765

- Prepublication history and additional supplemental material for this paper are available online. To view these files, please visit the journal online (http://dx.doi.org/10.1136/ bmjopen-2021-050765).

Received 03 March 2021 Accepted 05 September 2021

Check for updates

(c) Author(s) (or their employer(s)) 2021. Re-use permitted under CC BY-NC. No commercial re-use. See rights and permissions. Published by BMJ.

For numbered affiliations see end of article.

Correspondence to

Dr Anita Nitchingham;

a.nitchingham@unsw.edu.au

\section{ABSTRACT}

Introduction Delirium is one of the most common conditions diagnosed in hospitalised older people and is associated with numerous adverse outcomes, yet there are no proven pharmacological treatments. Recent research has identified cerebral glucose hypometabolism as a pathophysiological mechanism offering a therapeutic target in delirium. Insulin, delivered via the intranasal route, acts directly on the central nervous system and has been shown to enhance cerebral metabolism and improve cognition in patients with mild cognitive impairment and dementia. This trial will determine whether intranasal insulin can reduce the duration of delirium in older hospitalised patients.

Methods and analysis This is a prospective randomised, placebo-controlled, double-blind study with 6 months follow-up. One hundred patients aged 65 years or older presenting to hospital with delirium admitted under geriatric medicine will be recruited. Participants will be randomised to intranasal insulin detemir or placebo administered twice daily until delirium resolves, defined as Confusion Assessment Method (CAM) negative for 2 days, or discharge from hospital. The primary outcome measure will be duration of delirium using the CAM. Secondary outcome measures will include length of hospital stay, severity of delirium, adherence to treatment, hospital complications, new admission to nursing home, mortality, use of antipsychotic medications during hospital stay and cognitive and physical function at 6 months postdischarge. Ethics and dissemination This trial has been approved by the South Eastern Sydney Human Research and Ethics Committee. Dissemination plans include submission to a peer-reviewed journal for publication and presentation at scientific conferences.

Trial registration number ACTRN12618000318280.

\section{BACKGROUND}

Delirium is common, with figures reporting $10 \%-35 \%$ of older people are delirious on admission to hospital (prevalent delirium) and up to another $29 \%$ will become delirious during their admission (incident delirium). ${ }^{1}$ It is characterised by sudden and fluctuating disturbances in cognition, attention and
Strengths and limitations of this study

- The study design is pragmatic, inclusive and representative of real-world older hospitalised patients who are often omitted from research due to multimorbidity.

- The primary outcome, duration of delirium, is clinically relevant with longer duration of delirium predicting worse outcomes in patients.

- This is a single-site trial based in Sydney, Australia; therefore, generalisability may be restricted.

- Bedside assessment of delirium will occur daily rather than multiple times per day, meaning diurnal fluctuations in behaviour will be captured by record review and informant history.

- Patients in this study will be reviewed in person by trained assessors daily for up to 1-week postdischarge, however, assessment after 1 week is beyond the resources allocated for this trial.

awareness. $^{2}$ The sequelae of delirium are manifold and extend beyond the acute hospitalisation; increased mortality, new cognitive impairment, accelerated dementia, loss of independence and increased admission to nursing home. ${ }^{34}$ In older patients, delirium is independently associated with a twofold increase in mortality at 12 months. ${ }^{5}$ Longer duration and increased severity of delirium predict poorer outcomes in older patients. ${ }^{6}$

Studies suggest that only $30 \%$ of incident delirium is potentially preventable with nonpharmacological multimodal intervention. ${ }^{7}$ Current management focuses on identifying and treating the underlying cause of delirium combined with non-pharmacological interventions to provide an optimal environment for brain recovery and reduce the risk of potentially avoidable complications such as falls and pressure injuries.

Pharmacological management is focused on symptomatic control with antipsychotics. However, evidence does not support the use 
of antipsychotics for delirium and a recent randomised controlled trial demonstrated worsening symptoms and increased mortality. ${ }^{8}$ At this point in time, there are no proven pharmacological interventions to prevent or manage delirium for use on general hospital wards.

Delirium pathophysiology is poorly understood, although several hypotheses exist. ${ }^{10}$ These include neuroinflammation, ${ }^{11}$ neurotransmitter dysregulation, ${ }^{12}$ neuroendocrine dysregulation ${ }^{13}$ and neural network dysconnectivity. ${ }^{14}$ As delirium is a complex and heterogeneous disorder, it is likely that several of these mechanisms may contribute to the development of delirium with varying effect depending on pre-existing patient vulnerabilities and the aetiology of the acute precipitant. ${ }^{15}$ However, regardless of the underlying cause, delirium presents in a recognisable and stereotyped manner (phenotypically hypoactive, hyperactive and mixed) and the hypothesis that a 'final common pathway' may exist should not be disregarded.

Research has identified altered cerebral perfusion and metabolism as a feature of delirium. Delirious patients have higher cerebrospinal fluid lactate and lower neuronspecific enolase suggesting suppressed aerobic metabolism during an episode of delirium. ${ }^{16} 17$ Two studies have demonstrated cerebral glucose hypometabolism during delirium using fluorodeoxyglucose positron emission tomography (FDG-PET) ${ }^{18}{ }^{19}$ Haggstrom et al have demonstrated a correlation between posterior cingulate cortex hypometabolism and attention as well as evidence of improved cortical glucose metabolism with resolution of delirium. ${ }^{18}$ Neuroimaging studies using a variety of modalities have demonstrated reduced cerebral perfusion, decreased cerebral oxygenation and abnormal cerebral autoregulation during an episode of delirium. ${ }^{20}{ }^{21}$ As cerebral blood flow and metabolism are closely coupled and considered to reflect synaptic activity, ${ }^{22}$ correction of perfusion and metabolism abnormalities may improve clinical outcomes in delirium.

It is now well established that the brain is an insulin sensitive organ; insulin receptors are widely expressed in the brain, with greatest saturation in the corticolimbic structures. ${ }^{23}$ Insulin enhances learning and memory by modulating neuronal growth, metabolism, plasticity and cholinergic function. ${ }^{23} 24$

The role of glucose metabolism in the pathogenesis of neurodegenerative disease is a growing area of research. ${ }^{25}$ Mild Cognitive Impairment (MCI) and Alzheimer's dementia (AD) have been characterised as states of brain-specific insulin resistance and deficiency sometimes called 'type 3 diabetes'. ${ }^{26}$ Patients with early-stage AD demonstrate pronounced insulin and insulin-like growth factor deficiency and resistance which progress with severity of neurodegeneration..$^{23}$ Administration of intravenous insulin while maintaining fasting serum glucose levels improves memory in patients with Alzheimer's disease ${ }^{27}$ However, therapeutic administration of intravenous insulin is not feasible or safe due to the substantial risk of systemic hypoglycaemia.
The intranasal route of delivery provides a non-invasive and safe means of transporting insulin to the brain. A recent systematic review identified seven studies (total, $\mathrm{N}=293$ ) examining the effect of intranasal insulin on MCI or $\mathrm{AD}$, of which six demonstrated significant improvements in verbal memory. ${ }^{28}$ Positive outcomes in functional status were also observed. ${ }^{29-31}$ Improvements in attention, visuospatial memory and executive function have also been demonstrated in other populations. ${ }^{32-34}$

One randomised placebo controlled trial has assessed the effect of intranasal insulin on delirium prevention in a cohort of 80 older patients undergoing laparoscopic gastrointestinal tumour resection. ${ }^{35}$ The incidence of postoperative delirium within five days of surgery was lower in the intranasal group $(12.5 \%$ vs $47.5 \%, \mathrm{P}=0.001)$. There were no differences in blood glucose levels or adverse events between groups. ${ }^{35}$

Given that intranasal insulin improves cognition as well as cerebral perfusion and metabolism, this trial will investigate its potential role in treatment of delirium.

This randomised controlled trial will evaluate whether intranasal insulin, compared with placebo, can reduce the duration of delirium in older patients admitted under geriatric medicine.

\section{METHODS}

\section{Design}

This is a single site, randomised, double-blind, placebocontrolled trial of 100 older people diagnosed with delirium on admission to hospital (prevalent delirium). Figure 1 gives an overview of study design.

This research will be conducted in accordance with the Declaration of Helsinki. As required by the New South Wales Guardianship act 1987 (part 5), New South Wales Civil and Administrative Tribunal, approval to conduct this clinical trial has been obtained (case number 2017/00204946).

\section{Population}

The study population will comprise older people admitted under a geriatrician at a large tertiary hospital in metropolitan Sydney, Australia. Potential participants must be (A) diagnosed with prevalent delirium, (B) receiving inpatient care on the geriatric medicine wards, (C) age $>64$ years, (D) have a consenting 'person responsible' and (E) be enrolled in the trial within 48 hours of admission to hospital. People with known cognitive impairment and dementia will be included.

Exclusion criteria include (A) people who are haemodynamically unstable (based on treating physicians judgement guided by activation of a 'red zone response' on the New South Wales Health Standard Adult General Observation $\mathrm{Chart}^{36}$ ), (B) have a predicted life expectancy of less than 7 days as judged by the admitting geriatrician, (C) have an allergy to insulin detemir formulation or (D) a structural abnormality precluding the use of the nasal drug delivery device and (E) proven or suspected 


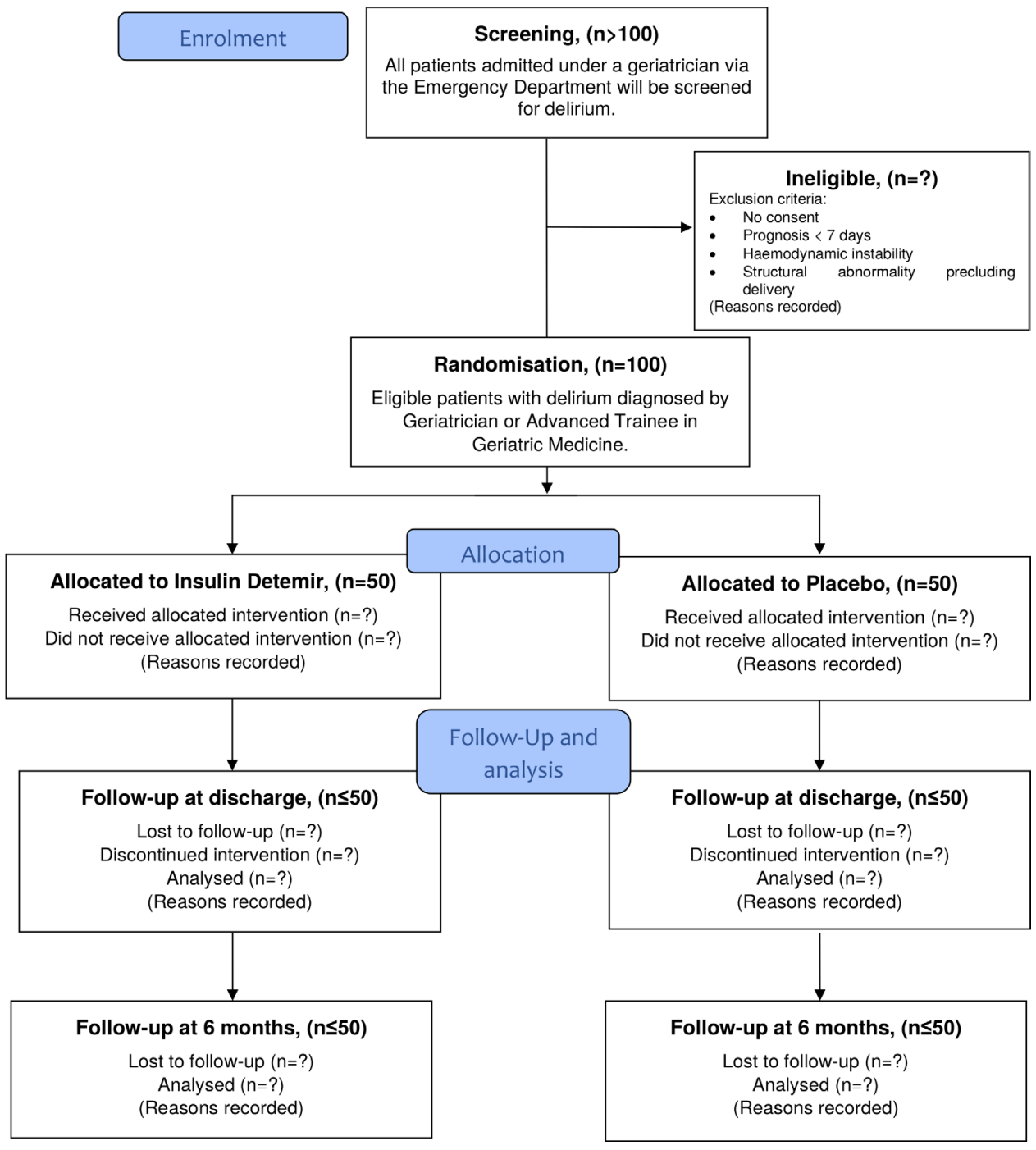

Figure 1 Flow of participants through the study.

COVID-19. People will also be excluded if consent is not obtained or they were previously enrolled in the trial. Non-English-speaking patients who are unable to participate in cognitive assessments will also be excluded. The trial will not include patients with incident delirium.

\section{Screening and evaluation of delirium}

Within the emergency department or on transfer to the geriatric medicine ward, all patients age $>64$ years will be screened by nursing staff for delirium using the Confusion Assessment Method (CAM) ${ }^{37} 38$ Patients with delirium diagnosed by a Geriatrician or Advanced Trainee in Geriatric Medicine using the Diagnostic and Statistical Manual of Mental Disorders Fifth Edition criteria will be considered for the trial. ${ }^{39}$

Study team members will use the CAM to conduct daily delirium assessments between 12:00 and 15:00 hours. All members of the study team will undergo formal training using the CAM. Bedside assessment will be supplemented by review of the medical records and collateral history from the patient's carer or ward staff where appropriate. The presence of delirium will be documented using the long form CAM. ${ }^{37}$ Delirium severity will be assessed using the Delirium Index (DI). ${ }^{40}$ Delirium clinical subtype will be assessed using the abbreviated version of the Delirium Motor Subtyping Scale. ${ }^{41}$ A Mini-Mental Status Examination will be used to complete the CAM and DI during the initial assessment and a standardised structured assessment will be conducted on subsequent days (see online supplemental appendix A).

Inter-rater reliability using the CAM and DI will be assessed using Cohen's kappa coefficient based on twenty patient reviews. ${ }^{42}$

\section{Consent}

Consent will involve conversations regarding the study risks, benefits and burdens between the researchers, patient and the 'person responsible' (substitute decision maker according to the New South Wales Guardianship Act 1987). To avoid a delay in initiation of the intervention, where a person responsible is unable to attend the hospital to sign the consent, an initial verbal consent may be granted (by phone) and written consent obtained as soon as possible. 
Table 1 List of measures collected at baseline (B), daily during intervention (D), hospital discharge (DC), 6 months follow-up $(6 \mathrm{M})$

\begin{tabular}{|c|c|c|c|c|c|}
\hline Information collected for all participants & B & D & DC & $6 \mathrm{M}$ & O \\
\hline \multicolumn{6}{|l|}{ Sociodemographics } \\
\hline Age, gender, education, occupation, handedness, marital status & $\mathrm{x}$ & & & & \\
\hline \multicolumn{6}{|l|}{ Medical and functional status } \\
\hline $\begin{array}{l}\text { Medical history, medication use, history of delirium and dementia, precipitating factor(s) in } \\
\text { delirium }\end{array}$ & $x$ & & & & \\
\hline Barthel Index, ${ }^{58}$ modified Instrumental Activities of Daily Living ${ }^{59}$ & $\mathrm{x}$ & & & $x$ & $\mathrm{~S}$ \\
\hline \multicolumn{6}{|l|}{$\begin{array}{l}\text { Charlson Comorbidity Index, }{ }^{70} \text { Acute Physiology, Age, Chronic Health Evaluation III, }{ }^{71} \text { Clinical } x \\
\text { Frailty Scale }\end{array}$} \\
\hline Baseline blood tests, apolipoprotein E4 status & $x$ & & & & \\
\hline Mini-Mental Status Examination ${ }^{73}$ & $x$ & & & $\mathrm{x}$ & \\
\hline Geriatric Depression Scale ${ }^{\star 74}$ & $\mathrm{x}$ & & & $\mathrm{x}$ & \\
\hline $\begin{array}{l}\text { Wechsler Adult Intelligence Scale IV Digit Span test, }{ }^{75} \text { Trail Making Test A and B, }{ }^{76} \text { Wechsler } \\
\text { Memorial Scale III Mental Control, }{ }^{77} \text { clock drawing task, word generation tasks and memory } \\
\text { impairment screen }\end{array}$ & & & & $x$ & $\mathrm{~S}$ \\
\hline $\begin{array}{l}\text { Duration of delirium, patients discharged with residual delirium will be reviewed daily for up } \\
\text { to } 1 \text {-week postdischarge }\end{array}$ & & $\mathrm{x}$ & & & $\mathrm{P}$ \\
\hline \multicolumn{6}{|l|}{ Inpatient Assessments and Safety } \\
\hline Percentage doses successfully administered & & & $\mathrm{x}$ & & $\mathrm{S}$ \\
\hline Length of stay & & & $\mathrm{x}$ & & $\mathrm{S}$ \\
\hline Mortality rate & & & $\mathrm{x}$ & $\mathrm{x}$ & S \\
\hline
\end{tabular}

Note: $\mathrm{x}=$ measurement to be taken at prespecified time, $\mathrm{O}=$ outcome measure, $\mathrm{P}=$ primary, $\mathrm{S}=$ secondary.

*If the patient is unable to engage during the initial assessment, repeat the test in subsequent days when the patient is able to engage.

Consent to remain in the trial will be obtained from the patient if capacity returns. Should the patient decline further involvement in the trial the researcher will ask the patient for consent to use trial data up until the time of withdrawal in the final analysis.

Consent will also be obtained for the collection and study of patient blood specimens.

\section{Assessment over the study period}

Table 1 highlights the measures to be undertaken at each predetermined time point. Measurements will be taken daily while receiving the intervention. Patient assessment will also occur at discharge from hospital and 6 months postdischarge.
Dementia status will be determined by a history of dementia diagnosis (informant history and medical record review) and/or an average Informant Questionnaire on Cognitive Decline in the Elderly (IQCODE) score $>3.44 .^{43}$

In addition to routine blood tests, $20 \mathrm{~mL}$ of blood will be taken from each patient and stored for later analysis, including the effect of apolipoprotein E4 (APOE4) status on study outcomes. ${ }^{44}$ Specimens will be frozen and stored at $-80^{\circ} \mathrm{C}$ in the University of New South Wales Lowy Biorepository.

\section{Randomisation and blinding}

Permutated block randomisation will be conducted with a block size of 4 and 25 blocks using a computer-generated 
algorithm. An independent clinical trials pharmacist will create the randomisation schedule which will be provided to the clinical trials pharmacy staff responsible for production and dispensing of the medication. Each vial of insulin or placebo will be labelled with a sequentially allocated randomisation number, which will become that patient's study number.

Participants, research and ward staff will be blinded to treatment allocation.

\section{Intervention}

Patients will receive 20 international units (IU) of longacting insulin (detemir) or a placebo of normal saline intranasally twice daily at 8:00 and 20:00 hours via a commercially available drug delivery device (ViaNase delivery device, Kurve Technology, Bothell, Washington, USA). This device has been used successfully in previous trials of intranasal insulin in cognitive impairment. ${ }^{30} 31$ The device will release $20 \mathrm{IU}$ insulin detemir or placebo intranasally via a small nose piece over a $40 \mathrm{~s}$ period. Patients will receive 20 s per nostril twice daily and during administration be instructed to breath normally through the nose.

Following intranasal administration, insulin enters the brain either through direct entry via the cribriform plate and the olfactory nerves or via specific receptors in the blood-brain barrier or a combination of the two. ${ }^{45}$ In 15-30 min, insulin peptides are detected within the cerebral cortex and hippocampus. ${ }^{46}$ Compared with the subcutaneous route, intranasal administration of insulin in mice demonstrates an approximately 2000-fold increase in the Area Under the Curve brain:plasma $_{\text {ratio, meaning at }}$ similar doses the intranasal route reaches comparable or increased brain insulin concentration but substantially lower plasma concentration. ${ }^{47}$

The total daily dose of $40 \mathrm{IU}$ of insulin detemir is based on research by Claxton et al demonstrating safety and efficacy in older patients with $\mathrm{AD}$. In this trial, 60 patients with mild cognitive impairment or mild-to-moderate $\mathrm{AD}$ received either placebo, $20 \mathrm{IU}$ of insulin detemir or $40 \mathrm{IU}$ of insulin detemir intranasally for 21 days. Participants receiving $40 \mathrm{IU}$ of insulin detemir demonstrated significant improvements in verbal and visuospatial working memory. No statistically significant effect was found in the 20 IU detemir group. No treatment-related severe adverse events were reported. ${ }^{44}$

Preprepared, spare vials and in-use devices will be stored between $2^{\circ} \mathrm{C}$ and $8^{\circ} \mathrm{C}$ in the ward medication fridge.

The medication will be administered by ward registered nurses specifically trained for the trial. Nurses will record challenges regarding administration of the intervention, including partially received or omitted doses, in the electronic patient record which will be reviewed by trial staff daily.

The intervention will cease following two consecutive CAM negative days; this criteria has been successfully adopted in other studies assessing delirium duration. ${ }^{48}$ The intervention will be discontinued for patients with subsyndromal delirium (defined by the presence of one or more CAM symptoms without meeting the criteria for delirium). ${ }^{49}$

Cessation of treatment with the study intervention will also occur if:

- The patient is discharged from the hospital.

- Patient or treating clinician requests discontinuation.

- Unacceptable side effects from study medications (defined by National Cancer Institute Common Criteria for Adverse Events; Common Terminology Criteria for Adverse Events version V.4.0).

- Participants who in the opinion of the investigator are not well enough to continue in the study.

- Adverse events related to the study medicine are unacceptable to the participant/carer or clinician in charge, for example, symptomatic or severe hypoglycaemia (blood sugar level $<3.0 \mathrm{mmol} / \mathrm{L}$ ).

- Treatment is deemed ineffective, defined as no improvement in DI over 7 days.

Patients withdrawn from the study will be included in statistical analysis on an intention-to-treat basis.

If delirium recurs after resolution of the initial episode (ie, hospital acquired delirium), the intervention will not be recommenced.

\section{Safety}

Studies have demonstrated that less than 3\% of intranasally delivered insulin is detectable in the serum and as a result intranasal insulin has a negligible risk of hypoglycaemia. ${ }^{2850}$ A systematic review on the safety of intranasal insulin included 38 studies $(\mathrm{N}=1092)$ and found no cases of hypoglycaemia or severe adverse events. ${ }^{51}$ The most commonly reported side effects were transient and local to the nasal area including nasal tingling and burning, less commonly rhinitis and nasal bleeding occurred.

Although the risk of hypoglycaemia is largely theoretical, blood glucose levels will be measured at baseline and four times daily during the study intervention (07:00, 13:00, 19:00 and 22:00 hours). As adequate and uninterrupted sleep is a core principle in delirium management and disturbed sleep can precipitate or exacerbate delirium, blood glucose levels will not be taken overnight.

Adverse events will be assessed daily through participant interview supplemented by review of the electronic medical record. Serious adverse events as defined by the International Conference on Harmonisation Guidelines for Good Clinical Practice will be reported in accordance with local ethics requirements. An independent data and safety monitoring board (DSMB) will oversee the study and meet after each twenty patients. Serious adverse events will be discussed with the lead investigator immediately and reported to the Human Research Ethics Committee (HREC) and trial DSMB within 24 hours.

Delirium is associated with a high in-hospital mortality rate, previously demonstrated to reach $35 \%$ in an older population. ${ }^{52}$ As such, a key role of DSMB will be to review all deaths and serious adverse events in detail to determine if the adverse event was in keeping with the natural 
history of the illness or could be attributed to the study intervention. ${ }^{53}$ Should concerns arise regarding patient safety the DSMB may request to unblind for decisionmaking purposes.

There are two main scenarios which could prompt DSMB to request termination of the study. First, if there are a significant number of serious adverse events possibly attributed to the intervention leading to patient safety concerns and second, significant benefit from the intervention. Should termination of the trial be requested, researchers would be unblinded and data analysis would occur. The HREC and participants would be informed the trial was stopped and reasons for termination given.

\section{Outcomes}

The primary and secondary outcomes are outlined in table 1 . The primary outcome will be duration of delirium in days. Delirium assessment will be conducted daily from enrolment until delirium resolution, defined as two consecutive days (48 hours) CAM negative. Patients discharged with delirium will be followed up in person daily for up to 1 week to assess for delirium resolution. Secondary outcomes will determine if intranasal insulin compared with placebo decreases acute length of hospital stay, reduces severity of delirium, reduces hospital complications, reduces new admission to nursing home, decreases mortality and decreases use of antipsychotic medications during an inpatient stay. Patients will be followed up at 6 months postdischarge to assess if intranasal insulin reduces mortality and preserves cognition and function. Adherence to the intervention will be measured by percentage of doses successfully administered.

\section{Sample size}

Power analysis (with 5\% significance and $80 \%$ power) was performed using published data which shows the mean duration of delirium clustered at approximately 8 days in geriatric medicine ward populations. ${ }^{54}{ }^{55}$ Power calculation shows reducing delirium duration by 2 days (from 8 days to 6 days) requires 36 in each arm for a total of 72 patients. Allowing for a $30 \%$ drop-out rate, a total of 100 participants will be sought.

\section{Statistical analysis}

Statistical analysis will be conducted using IBM SPSS Statistics 26 software. An intention-to-treat approach will be adopted for all analyses and statistical significance assumed at the level of $5 \%(\mathrm{p}<0.05)$. Baseline characteristics will be reported for the overall population and separately for each group.

The primary outcome, duration of delirium measured in days, will be analysed first with a Mann-Whitney U test which has high statistical power ${ }^{56}$ and then using survival analysis Cox proportional hazard method including dementia, nursing home status, severity of acute illness (Acute Physiology, Age, Chronic Health Evaluation III (APACHE III) ) and comorbidity as covariates. Sensitivity analysis will be conducted using normality-improving data transformations or gamma regression with a log link according to the distribution of the primary outcome. Analysis will include in hospital death as a competing risk. For the major secondary outcome, trajectory of delirium severity measured by the DI over time, a generalised linear mixed model will be used. Binary outcomes like mortality (in-hospital and at 6 months) and institutionalisation will be evaluated using a modified Poisson regression. ${ }^{57} \mathrm{~A}$ linear regression will assess possible preservation of function, measured by Barthel Index ${ }^{58}$ and modified Instrumental Activities of Daily Living, ${ }^{59}$ and for all other linear secondary outcomes. Bootstrapping will be applied if the models fail to satisfy the normality assumptions. For length of hospital stay, a log-linear or gamma regression with a $\log$ link will be implemented. The number of hospital complications and the use of antipsychotics during hospitalisation will be reported.

Subgroup analysis stratifying by age, sex, dementia and APOE status will be conducted.

\section{Data management}

Data will be collected by trained researchers and stored on a password-protected database. One researcher will be responsible for data entry while another member of the study team will monitor the accuracy of data by crosschecking a random $10 \%$ sample of subjects.

Paper files of individual records will be stored in a locked cabinet in a secure location accessible to authorised members of the study team only. Electronic data will be entered in a deidentified format and stored on a password-protected secure server. The complete data set will be stored on the University of New South Wales Data Archive and will be made available at the completion of the trial on reasonable request.

\section{Patient and public involvement}

A public representative approved trial concept, design and consent procedures as part of the application to New South Wales Civil and Administrative Tribunal.

\section{Ethics and dissemination}

The trial methods, protocol and consent procedures were approved by the South Eastern Sydney Human Research and Ethics Committee (HREC 16_320). Results of the trial will be published in biomedical journals and presented at international scientific conferences. Social media platforms will be used to inform the general public about the results. Authorship on publications related to this study will follow standard eligibility guidelines ensuring significant contribution.

\section{DISCUSSION}

Delirium is a debilitating condition commonly affecting older people in hospital for which there are no registered treatments. It has been consistently demonstrated that longer duration of delirium predicts worse outcomes, including higher mortality and new admission to residential aged care facility. ${ }^{60}$ Although the pathophysiological mechanisms are incompletely understood, it is probable 
that an episode of delirium causes irreversible neuronal damage leading to sustained cognitive and functional impairment, ${ }^{61}$ with prolonged delirium exposure leading to greater cerebral damage.

To date, there are no trials assessing intranasal insulin as a treatment for delirium, however, it could improve cognitive and clinical outcomes for delirious patients via a variety of mechanisms. Intranasal insulin increases cerebral perfusion ${ }^{3362-64}$ and increases or maintains cerebral glucose metabolism on FDG-PET. ${ }^{65}{ }^{66}$ In young healthy adults and patients with type 2 diabetes mellitus, intranasal insulin enhances functional connectivity within the default mode network, an important centre for higher cognitive processes in which delirious patients demonstrate dysconnectivity. ${ }^{146768}$ The hypothalamic-pituitaryadrenal (HPA) axis is also insulin responsive and following administration of intranasal insulin healthy populations demonstrate diminished saliva and plasma cortisol. ${ }^{3269}$ As aberrant HPA axis activity is hypothesised to contribute to delirium pathophysiology, modification of this pathway may also lead to improved outcomes. ${ }^{13}$

We anticipate this trial will be pragmatic, inclusive and representative of real-world geriatric medicine inpatients. As such, we will include patients with pre-existing dementia and those residing in residential aged care facilities. This vulnerable population is at highest risk for delirium yet commonly under-represented in therapeutic trials.

An important aspect of this study will be patient tolerability of an inhaled nasal solution twice daily. Ward registered nurses administering intranasal insulin will receive training in both administration and subsequent documentation of the intervention. We will report on adherence and patients will be analysed on an intention-to-treat basis.

As duration of delirium is perhaps the most clinically relevant outcome for both clinicians and patients, we have chosen this as the primary outcome for the trial. The mean duration of delirium in geriatric medicine inpatients has been demonstrated to be $8 \pm 9$ days, however, symptoms of delirium can persist for up to 12 months. ${ }^{54}$ We anticipate some patients, particularly those returning to high level care residential aged care facilities, will be discharged with delirium and this group will be followed up daily for up to 1 week to assess for delirium resolution. Daily assessment after 1 week is beyond the allocated resources for this trial.

If found to be efficacious, this would lead to multicentre trials to confirm these findings. There would also be the opportunity to further explore intranasal insulin in prevention of delirium and its role across settings, including in the intensive care and postoperative populations which also represent vulnerable patient groups.

Should the intervention reduce the duration of delirium the benefits to patients and their families could be significant, both in alleviating acute distress and longer-term negative sequelae of delirium. The treatment also has the potential to save significant financial resources related to both the acute treatment of delirium and the residual effects with regard to loss of independence and higher care needs after resolution of delirium. Finally, irrespective of the outcome, this trial will contribute to our understanding of the pathophysiological mechanisms of delirium particularly the role of impaired cerebral perfusion and metabolism.

\section{Author affiliations}

${ }^{1}$ Department of Geriatric Medicine, Prince of Wales Hospital, Sydney, New South Wales, Australia

${ }^{2}$ Prince of Wales Clinical School, University of New South Wales, Sydney, New South Wales, Australia

${ }^{3}$ Rural Clinical School, Coffs Harbour Health Campus, University of New South Wales, Coffs Harbour, New South Wales, Australia

${ }^{4}$ Flinders Centre for Epidemiology and Biostatistics, Flinders University, Adelaide, South Australia, Australia

${ }^{5}$ Department of Molecular \& Translational Science, Hudson Institute, Monash University, Melbourne, Victoria, Australia

${ }^{6}$ Faculty of Health, University of Technology Sydney, Sydney, New South Wales, Australia

${ }^{7}$ Falls, Balance and Injury Research Centre, Neuroscience Research Australia, Randwick, New South Wales, Australia

\section{Twitter Barbara Toson @BarbaraStats}

Acknowledgements The authors would like to acknowledge Robert Welschinger (Research Officer), Joanne 0'Brien and the Pharmacy and Geriatric Departments for their support. AN is supported through an Australian Government Research Training Program Scholarship (University of New South Wales Scientia PhD Scholarship).

Contributors GC initiated the study and is the trial sponsor. AN, AM and GC designed the original protocol. JC and MA provided substantial input in study processes and logistics. BTu provided expertise in the area of Endocrinology. BTo provided extensive guidance on the statistical analysis. All authors contributed to the writing of the manuscript and approved the final version.

Funding This trial is financially supported by the JJ Mason and HS Williams Memorial Foundation, The Julia Lowy Foundation and the Harry Triguboff Foundation. Award/Grant number not applicable.

Disclaimer The funding bodies have no role in trial design, trial conduct, data management, analysis, interpretation of the data, writing of the manuscript or decision to publish.

Competing interests MA receives delirium clinical trial funding from Cancer Australia.

Patient consent for publication Not applicable.

Provenance and peer review Not commissioned; externally peer reviewed.

Supplemental material This content has been supplied by the author(s). It has not been vetted by BMJ Publishing Group Limited (BMJ) and may not have been peer-reviewed. Any opinions or recommendations discussed are solely those of the author(s) and are not endorsed by BMJ. BMJ disclaims all liability and responsibility arising from any reliance placed on the content. Where the content includes any translated material, BMJ does not warrant the accuracy and reliability of the translations (including but not limited to local regulations, clinical guidelines, terminology, drug names and drug dosages), and is not responsible for any error and/or omissions arising from translation and adaptation or otherwise.

Open access This is an open access article distributed in accordance with the Creative Commons Attribution Non Commercial (CC BY-NC 4.0) license, which permits others to distribute, remix, adapt, build upon this work non-commercially, and license their derivative works on different terms, provided the original work is properly cited, appropriate credit is given, any changes made indicated, and the use is non-commercial. See: http://creativecommons.org/licenses/by-nc/4.0/.

ORCID iD

Anita Nitchingham http://orcid.org/0000-0002-9215-0844

\section{REFERENCES}

1 Siddiqi N, House AO, Holmes JD. Occurrence and outcome of delirium in medical in-patients: a systematic literature review. Age Ageing 2006;35:350-64.

2 Caplan G. Managing delirium in older patients. Aust Prescr 2011;34:16-18. 
3 Witlox J, Eurelings LSM, de Jonghe JFM, et al. Delirium in elderly patients and the risk of postdischarge mortality, institutionalization, and dementia: a meta-analysis. JAMA 2010;304:443-51.

4 McCusker J, Cole MG, Dendukuri N, et al. Does delirium increase hospital stay? J Am Geriatr Soc 2003;51:1539-46.

5 McCusker J, Cole M, Abrahamowicz M, et al. Delirium predicts 12-month mortality. Arch Intern Med 2002;162:457-63.

6 Jackson TA, Wilson D, Richardson S, et al. Predicting outcome in older hospital patients with delirium: a systematic literature review. Int J Geriatr Psychiatry 2016;31:392-9.

7 Siddiqi N, Harrison JK, Clegg A, et al. Interventions for preventing delirium in hospitalised non-ICU patients. Cochrane Database Syst Rev 2016;3:CD005563.

8 Neufeld KJ, Yue J, Robinson TN, et al. Antipsychotic medication for prevention and treatment of delirium in hospitalized adults: a systematic review and meta-analysis. J Am Geriatr Soc 2016;64:705-14.

9 Agar MR, Lawlor PG, Quinn S, et al. Efficacy of oral risperidone, haloperidol, or placebo for symptoms of delirium among patients in palliative care: a randomized clinical trial. JAMA Intern Med 2017;177:34-42.

10 Wilson JE, Mart MF, Cunningham C, et al. Delirium. Nature Reviews Disease Primers 2020;6.

11 Cerejeira J, Firmino H, Vaz-Serra A, et al. The neuroinflammatory hypothesis of delirium. Acta Neuropathol 2010;119:737-54.

12 Hshieh TT, Fong TG, Marcantonio ER, et al. Cholinergic deficiency hypothesis in delirium: a synthesis of current evidence. J Gerontol A Biol Sci Med Sci 2008;63:764-72.

13 MacLullich AMJ, Ferguson KJ, Miller T, et al. Unravelling the pathophysiology of delirium: a focus on the role of aberrant stress responses. J Psychosom Res 2008;65:229-38.

14 Choi S-H, Lee H, Chung T-S, et al. Neural network functional connectivity during and after an episode of delirium. Am J Psychiatry 2012;169:498-507.

15 Maldonado JR. Delirium pathophysiology: an updated hypothesis of the etiology of acute brain failure. Int $J$ Geriatr Psychiatry 2018;33:1428-57.

16 Caplan GA, Kvelde T, Lai C, et al. Cerebrospinal fluid in long-lasting delirium compared with Alzheimer's dementia. J Gerontol A Biol Sci Med Sci 2010;65:1130-6.

17 Kealy J, Murray C, Griffin EW. Acute inflammation alters energy metabolism in mice and humans: role in sickness-induced hypoactivity impaired cognition and delirium. bioRxiv 2019;642967.

18 Haggstrom LR, Nelson JA, Wegner EA, et al. 2- ${ }^{18}$ F-fluoro-2deoxyglucose positron emission tomography in delirium. $J$ Cereb Blood Flow Metab 2017;37:3556-67.

$19 \mathrm{Ma} \mathrm{H}$, Liao Y, Mo Y, et al. Decreased cerebral glucose metabolism in elderly patients with postoperative delirium: a case-control study. $J$ Anesth Perioper Med 2017;4.

20 Nitchingham A, Kumar V, Shenkin S, et al. A systematic review of neuroimaging in delirium: predictors, correlates and consequences. Int J Geriatr Psychiatry 2018;33:1458-78.

21 Caplan GA, Lan Z, Newton L, et al. Transcranial Doppler to measure cerebral blood flow in delirium superimposed on dementia. A cohort study. J Am Med Dir Assoc 2014;15:355-60.

22 Mosconi L. Glucose metabolism in normal aging and Alzheimer's disease: methodological and physiological considerations for PET studies. Clin Transl Imaging 2013;1:217-33.

23 de la Monte SM. Intranasal insulin therapy for cognitive impairment and neurodegeneration: current state of the art. Expert Opin Drug Deliv 2013;10:1699-709.

24 Blázquez E, Velázquez E, Hurtado-Carneiro V, et al. Insulin in the brain: its pathophysiological implications for states related with central insulin resistance, type 2 diabetes and Alzheimer's disease. Front Endocrinol 2014:5:161.

25 Kuehn BM. In Alzheimer research, glucose metabolism moves to center stage. JAMA 2020;323:297.

26 de la Monte SM, Wands JR. Alzheimer's Disease is Type 3 Diabetes-Evidence Reviewed. J Diabetes Sci Technol 2008;2:1101-13.

27 Craft S, Newcomer J, Kanne S, et al. Memory improvement following induced hyperinsulinemia in Alzheimer's disease. Neurobiol Aging 1996:17:123-30.

28 Avgerinos KI, Kalaitzidis G, Malli A, et al. Intranasal insulin in Alzheimer's dementia or mild cognitive impairment: a systematic review. J Neurol 2018;265:1497-510.

29 Reger MA, Watson GS, Green PS, et al. Intranasal insulin improves cognition and modulates beta-amyloid in early AD. Neurology 2008;70:440-8.

30 Claxton A, Baker LD, Hanson A, et al. Long acting intranasal insulin Detemir improves cognition for adults with mild cognitive impairment or early-stage Alzheimer's disease dementia. J Alzheimers Dis 2015:45:1269-70.

31 Craft Set al. Intranasal insulin therapy for Alzheimer disease and amnestic mild cognitive impairment. Arch Neurol 2012:69:29-38.

32 Benedict C, Hallschmid M, Hatke A, et al. Intranasal insulin improves memory in humans. Psychoneuroendocrinology 2004;29:1326-34.

33 Novak V, Milberg W, Hao Y, et al. Enhancement of vasoreactivity and cognition by intranasal insulin in type 2 diabetes. Diabetes Care 2014;37:751-9.

34 McIntyre RS, Soczynska JK, Woldeyohannes HO, et al. A randomized, double-blind, controlled trial evaluating the effect of intranasal insulin on neurocognitive function in euthymic patients with bipolar disorder. Bipolar Disord 2012;14:697-706.

35 Huang Q, Li Q, Qin F, et al. Repeated preoperative intranasal administration of insulin decreases the incidence of postoperative delirium in elderly patients undergoing laparoscopic radical gastrointestinal surgery: a randomized, placebo-controlled, double-blinded clinical study. Am J Geriatr Psychiatry 2021 doi:10.1016/j.jagp.2021.02.043. [Epub ahead of print: $23 \mathrm{Feb}$ 2021].

36 Clinical_Excellence_Commission. Nsw health standard adult observation chart 2019. Available: https://www.cec.health.nsw.gov. au/keep-patients-safe/deteriorating-patient-program/between-theflags/observation-charts

37 Inouye SK, van Dyck CH, Alessi CA, et al. Clarifying confusion: the confusion assessment method. A new method for detection of delirium. Ann Intern Med 1990;113:941-8.

38 Inouye SK. The short confusion assessment method (short cam): training manual and coding guide. Boston: Hospital Elder Life Program, 2014

39 American Psychiatric Association. Diagnostic and statistical manual of mental disorders. 5th ed. Washington, DC: American Psychiatric Pub, 2013.

40 McCusker J, Cole MG, Dendukuri N, et al. The delirium index, a measure of the severity of delirium: new findings on reliability, validity, and responsiveness. J Am Geriatr Soc 2004;52:1744-9.

41 Meagher D, Adamis D, Leonard M, et al. Development of an abbreviated version of the delirium motor subtyping scale (DMSS-4). Int Psychogeriatr 2014;26:693-702.

42 McHugh ML. Interrater reliability: the kappa statistic. Biochem Med 2012;22:276-82.

43 Jorm AF. The informant questionnaire on cognitive decline in the elderly (IQCODE): a review. Int Psychogeriatr 2004;16:275-93.

44 Claxton A, Baker LD, Hanson A, et al. Long-Acting intranasal insulin detemir improves cognition for adults with mild cognitive impairment or early-stage Alzheimer's disease dementia. J Alzheimers Dis 2015;44:897-906.

45 Henkin RI. Intranasal insulin: from nose to brain. Nutrition 2010;26:624-33.

46 Craft S, Claxton A, Baker LD, et al. Effects of regular and long-acting insulin on cognition and Alzheimer's disease biomarkers: a pilot clinical trial. J Alzheimers Dis 2017:57:1325-34.

47 Nedelcovych MT, Gadiano AJ, Wu Y. Pharmacokinetics of intranasal versus subcutaneous insulin in the mouse. ACS Chem Neurosci 2017;9.

48 Adamis D, Devaney A, Shanahan E, et al. Defining 'recovery' for delirium research: a systematic review. Age Ageing 2015;44:318-21.

49 Cole MG, Ciampi A, Belzile E, et al. Subsyndromal delirium in older people: a systematic review of frequency, risk factors, course and outcomes. Int J Geriatr Psychiatry 2013;28:771-80.

50 Salameh TS, Bullock KM, Hujoel IA, et al. Central nervous system delivery of intranasal insulin: mechanisms of uptake and effects on cognition. J Alzheimers Dis 2015;47:715-28.

51 Schmid V, Kullmann S, Gfrörer W, et al. Safety of intranasal human insulin: a review. Diabetes Obes Metab 2018;20:1563-77.

52 Eeles EMP, Hubbard RE, White SV, et al. Hospital use, institutionalisation and mortality associated with delirium. Age Ageing 2010;39:470-5

53 Cook D, Lauzier F, Rocha MG, et al. Serious adverse events in academic critical care research. CMAJ 2008:178:1181-4.

54 Rockwood K. The occurrence and duration of symptoms in elderly patients with delirium. J Gerontol 1993;48:M162-6.

55 McCusker J, Cole M, Dendukuri N, et al. The course of delirium in older medical inpatients: a prospective study. $J$ Gen Intern Med 2003;18:696-704.

56 Chazard E, Ficheur G, Beuscart J-B, et al. How to compare the length of stay of two samples of inpatients? A simulation study to compare type I and type II errors of 12 statistical tests. Value Health 2017;20:992-8.

57 Zou G. A modified poisson regression approach to prospective studies with binary data. Am J Epidemiol 2004;159:702-6. 
58 Mahoney FI, Barthel DW. Functional evaluation: the BARTHEL index. Md State Med J 1965;14:61-5.

59 Katz S, Ford AB, Moskowitz RW, et al. Studies of illness in the aged. The index of ADL: a standardized measure of biological and psychosocial function. JAMA 1963;185:914-9.

60 Cole MG, Ciampi A, Belzile E, et al. Persistent delirium in older hospital patients: a systematic review of frequency and prognosis. Age Ageing 2009;38:19-26.

61 Fong TG, Davis D, Growdon ME, et al. The interface between delirium and dementia in elderly adults. Lancet Neurol 2015:14:823-32.

62 Schilling TM, Ferreira de Sá DS, Westerhausen R, et al. Intranasal insulin increases regional cerebral blood flow in the insular cortex in men independently of cortisol manipulation. Hum Brain Mapp 2014;35:1944-56.

63 Akintola AA, van Opstal AM, Westendorp RG, et al. Effect of intranasally administered insulin on cerebral blood flow and perfusion; a randomized experiment in young and older adults. Aging 2017;9:790-802.

64 Rajasekar N, Nath C, Hanif K, et al. Intranasal insulin improves cerebral blood flow, Nrf-2 expression and BDNF in STZ (ICV)induced memory impaired rats. Life Sci 2017;173:1-10.

65 Chen Y, Guo Z, Mao Y-F, et al. Intranasal insulin ameliorates cerebral hypometabolism, neuronal loss, and astrogliosis in streptozotocin-induced Alzheimer's rat model. Neurotox Res 2018;33:716-24

66 Craft S, Baker LD, Montine TJ, et al. Intranasal insulin therapy for Alzheimer disease and amnestic mild cognitive impairment: a pilot clinical trial. Arch Neurol 2012;69:29.
67 Kullmann S, Heni M, Veit R, et al. Intranasal insulin enhances brain functional connectivity mediating the relationship between adiposity and subjective feeling of hunger. Sci Rep 2017;7:1627.

68 Zhang H, Hao Y, Manor B, et al. Intranasal insulin enhanced restingstate functional connectivity of hippocampal regions in type 2 diabetes. Diabetes 2015;64:1025-34.

69 Bohringer A, Schwabe L, Richter S, et al. Intranasal insulin attenuates the hypothalamic-pituitary-adrenal axis response to psychosocial stress. Psychoneuroendocrinology 2008;33:1394-400.

70 Charlson M, Szatrowski TP, Peterson J, et al. Validation of a combined comorbidity index. J Clin Epidemiol 1994;47:1245-51.

71 Knaus WA, Wagner DP, Draper EA, et al. The APACHE III prognostic system. risk prediction of hospital mortality for critically ill hospitalized adults. Chest 1991;100:1619-36.

72 Rockwood K, Song X, MacKnight C, et al. A global clinical measure of fitness and frailty in elderly people. CMAJ 2005;173:489-95.

73 Folstein MF, Robins LN, Helzer JE. The Mini-Mental state examination. Arch Gen Psychiatry 1983;40:812.

74 Yesavage JA, Brink TL, Rose TL, et al. Development and validation of a geriatric depression screening scale: a preliminary report. $J$ Psychiatr Res 1982;17:37-49.

75 Wechsler D. Wechsler adult intelligence scale. 4th ed, 2008.

76 Reitan RM, Wolfson D. The Halstead-Reitan neuropsychological test battery : theory and clinical interpretation. Tucson, Ariz. Neuropsychology Press, 1985.

77 Millis SR, Malina AC, Bowers DA, et al. Confirmatory factor analysis of the Wechsler memory Scale-III. J Clin Exp Neuropsychol 1999;21:87-93.

78 Buschke H, Kuslansky G, Katz M, et al. Screening for dementia with the memory impairment screen. Neurology 1999;52:231. 